\title{
High-dose glucocorticoids increase serum levels of soluble IL-6 receptor $\alpha$ and its ratio to soluble gp 130: an additional mechanism for early increased bone resorption
}

Andrea Dovio $^{1}$, Laura Perazzolo ${ }^{1}$, Laura Saba ${ }^{1}$, Angela Termine ${ }^{1}$, Marco Capobianco $^{2}$, Antonio Bertolotto ${ }^{2}$ and Alberto Angeli ${ }^{1}$

${ }^{1}$ Medicina Interna I, Dipartimento di Scienze Cliniche e Biologiche and ${ }^{2}$ CRESM-Neurobiologia Clinica, University of Turin, A.S.O. San Luigi, Regione Gonzole 10, 10043 Orbassano (TO), Italy

(Correspondence should be addressed to A Dovio; Email: andrea.dovio@unito.it)

\begin{abstract}
Objective: Glucocorticoids (GCs) at pharmacological doses stimulate bone resorption. Mechanisms of this action are unclear. The osteoclastogenic cytokine interleukin (IL)- 6 acts through an oligomeric receptor consisting of two subunits, gp 80 (or IL- 6 receptor $\alpha$, IL-6R $\alpha$ ) and gp130; both exist in membrane and soluble forms. Soluble IL-6R $\alpha(\mathrm{sIL}-6 \mathrm{R} \alpha)$ enhances, while sgp130 inhibits IL-6 signalling. In vitro, GCs enhance many effects of IL- 6 by up-regulation of IL- $6 \mathrm{R} \alpha$. The aim of the present study was to assess acute changes of IL- 6 system in the peripheral blood of patients given high-dose GCs. Subjects and methods: Serum levels of IL-6, sIL-6R $\alpha$, sgp130 and bone turnover markers were assessed before and each day during treatment in 24 multiple sclerosis (MS) patients undergoing high-dose (prednisolone, $15 \mathrm{mg} / \mathrm{kg}$ per day), short-term (3 to 5 days) intravenous GC therapy for relapse at the Regional Multiple Sclerosis Centre.

Results: An immediate and marked fall of osteocalcin and an early increase of C-terminal telopeptide of type I collagen were already noticed at day $2(P<0.001$ and $P<0.02$, respectively); both became more apparent in the subsequent days. IL-6 was always below or near the detection limit of our ELISA. sgp130 showed a slight increase. sIL-6R $\alpha$ significantly increased, peaking at day 4 $(P<0.01)$. However, inter-individual variability of response was noticed. Four patients showed a slight decrease, while no change was observed in one patient and an increase was noticed in the remaining nineteen (maximum change ranging from $+10 \%$ to $+67 \%$ with respect to baseline). In these patients, a significant increase of sIL-6R $\alpha / \operatorname{sgp} 130$ ratio was apparent. No correlation was found between bone turnover markers and any measured component of the IL-6 system.

Conclusions: sIL-6R $\alpha$ and sIL-6R $\alpha /$ sgp130 ratio are precociously increased in the peripheral blood of the vast majority of patients given high-dose, intravenous GCs. The increase of systemically available sIL-6R $\alpha$ conceivably results in the enhancement of IL-6-dependent osteoclastogenesis. The role of such a mechanism in the bone loss observed in inflammatory and immune-mediated diseases (where abundancy of IL-6 in the bone microenvironment is expected) requires further investigation.
\end{abstract}

European Journal of Endocrinology 154 745-751

\section{Introduction}

Glucocorticoid (GC)-induced osteoporosis is the leading form of secondary osteoporosis. Chronic GC treatment is associated with atraumatic fractures in 30 to $50 \%$ of patients. Increased risk of fracture is already apparent after 3 months of therapy. GCs affect bone through immediate and sustained decrease of bone formation together with early and transient increase of bone resorption (1-2). Mechanisms of increased bone resorption have been scarcely investigated. Weinstein et al. have recently shown that GCs may act directly on murine osteoclasts to prolong their lifespan (3).
However, data on direct actions of GCs on osteoclast differentiation, activity and apoptosis are conflicting. GC receptors have been inconsistently found in human osteoclasts depending on cellular model and detection tecnique (4-5). Nongenomic effects are conceivable, but have not been documented so far (6). Most authors agree that GCs may act on osteoclasts indirectly, cells of the stromal-osteobastic lineage being the main target of GC action in the bone microenvironment (1). Up- and down-regulation of RANKL and osteoprotegerin (OPG) expression in these cells, hence an increased RANKL/OPG ratio, has been recently proposed as a mechanism of increased bone resorption (7). 
Another possible pathway involves up-regulation of IL-6 signalling. IL-6 has long been known as a potent osteoclastogenic cytokine, involved in the pathological bone resorption of a number of bone diseases, including post-menopausal ostoporosis, Paget's disease of bone and skeletal metastases (8). The main source of IL-6 in the bone microenvironment is likely to reside in the stromal and osteoblastic cells. IL-6 acts through an oligomeric membrane receptor consisting of two subunits, known as gp80 (or IL-6 receptor $\alpha$, IL-6R $\alpha$ ) and gp130. gp130 is the signal-transducing molecule; it is shared by different oligomeric receptors for a family of cytokines including IL-6, IL-11, oncostatin $M$, leukemia inhibitory factor and others. IL-6R $\alpha$ is the specific ligand-binding subunit (9). Udagawa et al. have suggested that the ability of IL- 6 to induce osteoclast differentiation depends on signalling mediated by IL-6R $\alpha$ expressed on osteoblastic cells but not on osteoclast progenitors (10). The major effect of IL- 6 could be an up-regulation of RANKL (11-12). Nonetheless, recent work suggests that IL-6 may also exert RANKL-independent pro-osteoclastogenic effects (13).

Soluble forms of both IL-6R $\alpha$ (sIL-6R $\alpha)$ and gp130 (sgp130) have been described in several biological fluids, including blood. sIL-6R $\alpha$ and sgp130 are generated by either proteolytic cleavage of membrane molecules or translation of alternatively spliced mRNAs. Interestingly enough, IL-6 may bind to sIL-6R $\alpha$ forming an IL-6/sIL-6R $\alpha$ complex which is able to bind membrane gp130, leading to signal transduction. Activation mediated by ligand/soluble receptor subunits is called trans-signalling (14). In contrast, sgp130 may bind soluble and membrane-bound IL-6/IL-6R $\alpha$ complexes and prevent interaction with membrane gp130, hence signal transduction. Therefore, sgp130 appears to be an endogenous antagonist of IL-6 (15).

GCs up-regulate expression of both IL-6R $\alpha$ (10) and gp130 (16) in cells of the stromal-osteoblastic lineage. Accordingly, they are able to enhance the osteoclastogenic activity of IL- 6 at least under peculiar experimental conditions in vitro $(10,17)$. To the best of our knowledge, no data have been reported on the effects of GC administration on serum sIL-6R $\alpha$ and sgp130 in relation to bone resorption. The aim of the present study was to assess serum sIL-6R $\alpha, \operatorname{sgp} 130$ and bone turnover markers in a group of multiple sclerosis (MS) patients undergoing high-dose, short-term intravenous GC therapy for relapse.

\section{Materials and methods}

\section{Study population}

The study was performed in the Department of Internal Medicine and the Centre for Research and Therapy on Multiple Sclerosis at San Luigi Hospital, Orbassano (Turin, Italy). All participants gave written informed consent before enrollment. The study protocol and informed consent documents were prepared according to the Declaration of Helsinki and subsequent relevant integrations, and approved by the local ethical review board. Patients with relapsing MS were diagnosed according to criteria by Poser et al. (18). Exclusion criteria were: history of diseases affecting bone, prolonged immobilization ( $>3$ weeks) and/or treatment with any drug documented to influence bone metabolism in humans in the previous 6 months.

Twenty-four patients ( 16 female, 8 male; age: median 36.5 , range 25-61 years) were recruited. Demographics, clinical data and baseline laboratory results of the study population are reported in Table 1.14 out of 24 patients were on interferon (IFN)- $\beta$ therapy at recruitment, the mean duration of previous treatment being 23 months; none of these patients stopped IFN- $\beta$ therapy at the beginning of the study. No calcium and vitamin D supplements were given. Methylprednisolone $(15 \mathrm{mg} / \mathrm{kg}$ per day) diluted in $250 \mathrm{ml}$ of saline was infused for $2 \mathrm{~h}$ in the morning, for 3 to 5 days, according to individual clinical response as assessed by experienced neurologists of the Centre and as a function of adopted protocols. No concomitant medication was administered.

\section{Biochemical analysis}

Each morning, after overnight fast and before GC infusion, a sampling cannula was inserted in a vein in antecubital fossa and flushed with $1 \mathrm{ml}$ sterile heparinized saline. Blood collection was performed after $30 \mathrm{~min}$ resting. Second-void urine samples also were collected.

Each day measurements of serum calcium, phosphorus, PTH, osteocalcin (OC), carboxyterminal telopeptide of type I collagen (CTX), IL-6, sIL-6R $\alpha$ and sgp130 were performed. On day 1 , serum 25-hydroxyvtamin D (25-OHD) was also measured.

Table 1 Demographics, clinical data and baseline laboratory results of the study population. Data are expressed as mean \pm S.E.M. (range).

\begin{tabular}{ll}
\hline & Values \\
\hline Age (years) & $38 \pm 2(25-61)$ \\
Number of females/males & $16 / 8$ \\
BMl $\left(\mathrm{kg} / \mathrm{m}^{2}\right)$ & $23.0 \pm 0.6(19.5-33.2)$ \\
Smokers & $3 / 24$ \\
Disease duration (years) & $9 \pm 1(1-23)$ \\
EDSS & $2.9 \pm 0.4(1-8)$ \\
Patients on treatment & $14 / 24$ \\
with interferon- $\beta$ & \\
Serum calcium & $2.19 \pm 0.05(1.70-2.47) \mathrm{mmol} / \mathrm{l}$ \\
& {$[8.8 \pm 0.2(6.8-9.9) \mathrm{mg} / \mathrm{dl}]$} \\
Serum phosphorus & $1.03 \pm 0.03(0.65-1.32) \mathrm{mmol} / \mathrm{l}$ \\
& {$[3.2 \pm 0.1(2.0-4.1) \mathrm{mg} / \mathrm{dll}]$} \\
PTH & $61 \pm 5(30-129) \mathrm{pg} / \mathrm{ml}$ \\
& {$[61 \pm 5(30-129) \mathrm{ng} / \mathrm{l}]$} \\
$25-\mathrm{OHD}$ & $24 \pm 4(7-83) \mathrm{ng} / \mathrm{ml}$ \\
& {$[60 \pm 10(17-207) \mathrm{nmol} / \mathrm{l}]$} \\
\hline
\end{tabular}


Serum calcium, phosphorus and albumin were measured by Aeroset System (Abbott Laboratories, Abbott Park, IL, USA), routinely used in the hospital laboratory. Serum calcium levels were always corrected for serum albumin as follows: corrected calcium $(\mathrm{mmol} / \mathrm{l})=$ total calcium $(\mathrm{mmol} / \mathrm{l})+0.02(40-$ albumin $(\mathrm{g} / \mathrm{l})$ ). Serum PTH was measured by chemiluminescence immunoassay for intact PTH (Nichols Institute Diagnostics, San Clemente, CA, USA). 25OHD was measured by RIA (Immunodiagnostic Systems, Boldon, UK). ELISAs were used for OC, CTX (Osteometer Biotech, Herlev, Denmark), IL-6, sIL-6R $\alpha$ and sgp130 (R\&D Systems Quantikine, Abingdon, UK). Ranges, minimum detectable concentrations, intra- and inter-assay coefficients of variation were as follows: OC: $2-68.1 \mathrm{ng} / \mathrm{ml} ; 0.4 \mathrm{ng} / \mathrm{ml} ; 2.6 \%$ and 9.1\%; CTX: $0.156-2.562 \mathrm{ng} / \mathrm{ml} ; 0.01 \mathrm{ng} / \mathrm{ml} ; 2.5 \%$ and 9\%; IL-6: $3.12-300 \mathrm{pg} / \mathrm{ml} ; 0.7 \mathrm{pg} / \mathrm{ml} ; 2.7 \%$ and 5.4\%; sIL-6R $\alpha$ : $31.2-2000 \mathrm{pg} / \mathrm{ml} ; 11 \mathrm{pg} / \mathrm{ml} ; \quad 2.6 \%$ and $5.9 \%$; sgp130: $0.25-16 \mathrm{ng} / \mathrm{ml} ; \quad 0.08 \mathrm{ng} / \mathrm{ml}$; $2.3 \%$ and $5 \%$.

\section{Statistical methods}

Statistical analysis of data was performed with Statistica 6.0 software package (Statsoft Inc, Tulsa, OK, USA). Results are presented as mean \pm S.E.M. Assessment of changes during GC treatment was performed by Wilcoxon matched pair test; for multiple comparisons, Bonferroni correction was used. Correlations among variables were assessed by Spearman R analysis.

\section{Results}

In our series, serum 25-OHD levels resulted below the lower limit of normal range $(<20 \mathrm{ng} / \mathrm{ml}$ $(<50 \mathrm{nmol} / \mathrm{l}))$ in $12 / 24$ patients. Six patients showed hypocalcaemia $(<2.10 \mathrm{mmol} / \mathrm{l}(<8.2 \mathrm{mg} / \mathrm{dl}))$; in one of them hypophosphoraemia $(<0.81 \mathrm{mmol} / \mathrm{l}$ $(<2.5 \mathrm{mg} / \mathrm{dl}))$ was also present. Increased PTH levels were found in seven patients: in two of them calcemia was below the lower limit of the normal range, while it was normal in the remaining five. None of the patients had hypercalcaemia or hyperphosphoremia (Table 1). At baseline, CTX levels were higher in males than in females $(0.827 \pm 0.136$ (mean \pm S.E.M.) vs $0.421 \pm 0.058 \mathrm{ng} / \mathrm{ml}, P=0.01$ ), and PTH showed an inverse correlation with sIL-6R $\alpha$ levels (Spearman $\mathrm{R}-0.47, \mathrm{P}=0.03)$.

In the course of GC administration, no apparent changes of serum phosphorus and calcium were observed. PTH showed a slight decrease (Fig. 1), while a progressive increase was noticed for urinary calcium to creatinine ratio (Fig. 2). As far as bone turnover markers are concerned, an immediate and marked fall of OC (Fig. 3a) and an early increase of CTX (Fig. 3b) were already noticed at day $2 \quad(P<0.001$ and

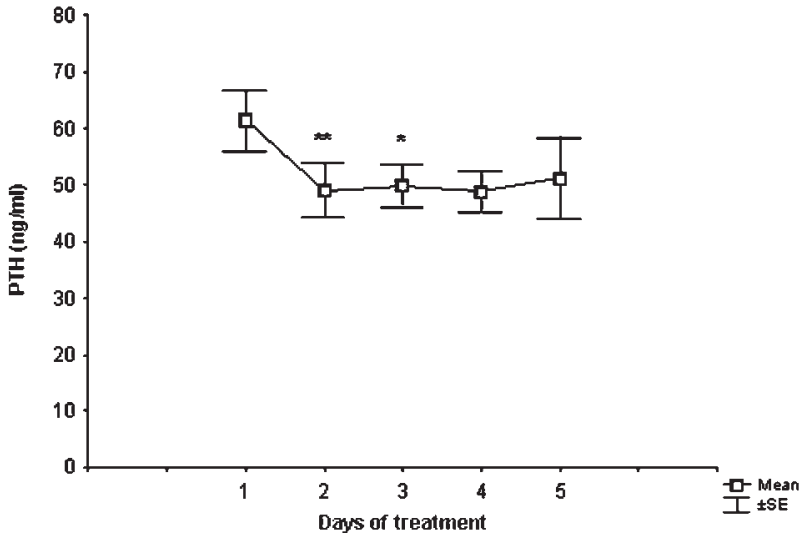

Figure 1 Effects of GC administration on PTH. PTH was measured on morning fasting blood samples before (day 1 ) and each day during treatment (days $2-5$ ). Data are expressed as mean \pm S.E.M. ${ }^{\star} P<0.05,{ }^{\star \star} P<0.01$ by Wilcoxon matched pair test.

$P<0.02$, respectively); both became more apparent in the subsequent days. Serum IL- 6 was always below or near the detection limit of our ELISA $(0.7 \mathrm{pg} / \mathrm{ml})$. Changes of sIL-6R $\alpha$ and sgp130 were evaluated in terms of absolute values, percent increase or decrease with respect to baseline values and area under the curve (AUC). Changes of sIL-6R $\alpha /$ sgp130 ratio were also assessed. sgp130 showed a slight increase (Figs $4 \mathrm{a}$ and $5 \mathrm{a}$ ), with great inter-individual variability: negative changes were observed in five patients, and positive changes in 19 , with maximum percent variations ranging from -6 to $-16 \%$ and from +6 to $+34 \%$ versus baseline, respectively. No difference in demographics, clinical and biochemical variables was found between the two subgroups.

As shown in Figs $4 \mathrm{~b}$ and $5 \mathrm{~b}$, as a group phenomenon sIL-6R $\alpha$ significantly increased, peaking at day 4 $(P<0.01)$. Again, inspection of individual patterns

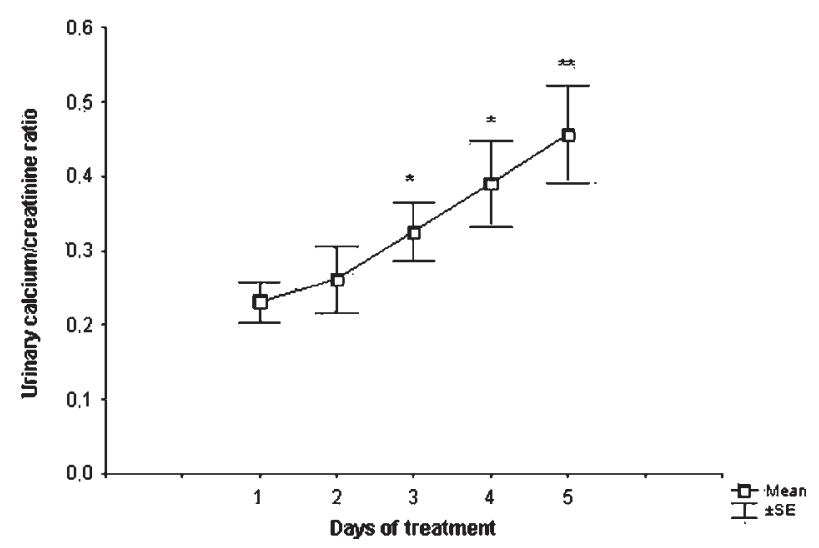

Figure 2 Effects of GC administration on urinary calcium to creatinine ratio. Calcium and creatinine were measured on second-void urine samples before (day 1) and each day during treatment (days 2-5). Data are expressed as mean \pm S.E.M. ${ }^{\star} P<0.05$, ${ }^{\star \star} P<0.01$ by Wilcoxon matched pair test. 
(a)

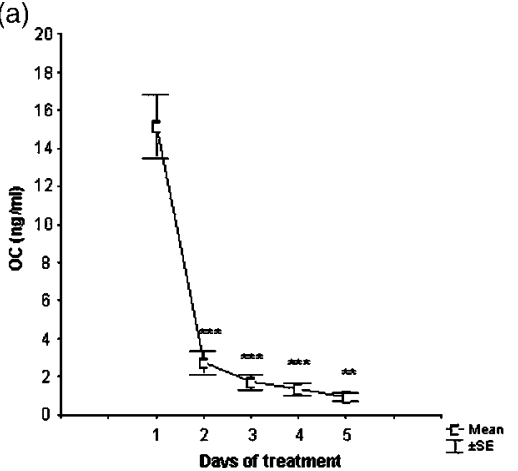

(b)

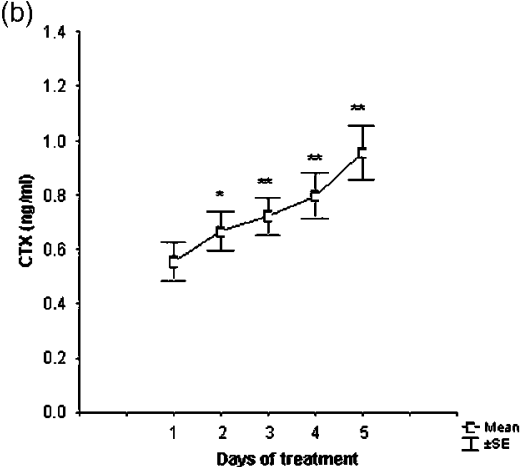

Figure 3 Effects of GC administration on serum bone markers. OC (a) and CTX (b) were measured on morning fasting blood samples before (day 1) and each day during treatment (days 2-5). Data are expressed as mean \pm S.E.M. ${ }^{*} P<0.05,{ }^{* *} P<0.01$ ${ }^{\star \star \star} P<0.001$ by Wilcoxon matched pair test. showed an ample inter-individual variability: when maximum percent changes were considered, four patients showed a slight decrease (from -10 to $-33 \%$ with respect to baseline), while no change was observed in one patient and an increase was noticed in the remaining 19 (from +10 to $+67 \%$ with respect to baseline); the latter were defined as 'responders'. When demographics, clinical and biochemical data were considered, no significant difference was found between responders and nonresponders, apart from baseline sIL-6R and PTH levels, which were respectively lower and higher in the former (sIL-6R $\alpha$ : $35 \pm 2$ vs $48 \pm 5 \mathrm{ng} / \mathrm{ml}, \quad P=0.009$; PTH: $66 \pm 6$ vs $46 \pm 7 \mathrm{pg} / \mathrm{ml}, P=0.05)$. When the whole population was considered, sIL-6R $\alpha / \operatorname{sgp} 130$ ratio was unchanged, but a significant increase was observed in the subgroup of responders (Fig. 6).

Finally, we calculated total and incremental AUCs of OC, CTX, sIL-6R $\alpha$ and sgp130. Due to variable duration of GC treatment, AUCs were adjusted as a function of days to allow for analysis. No correlation was found between bone turnover markers and all other analytes, in terms of either absolute or percent peak changes versus baseline values, or AUCs.

\section{Discussion}

The mechanisms of GC action in the bone microenvironment have been extensively studied in the last two decades. Inhibition of bone formation has long been recognized as the key pathogenetic event (1).
The immediate and marked fall of serum OC is clearly consistent with this view and confirms previous results published by us and others. Studies investigating the effects of GCs on bone resorption have yielded conflicting results (19-28). Discrepancies could be accounted for by different experimental conditions: the list of variables is long and includes human versus animal models, endogenous versus exogenous GC excess, pharmacokinetics and pharmacodynamics of the various GCs employed, doses and administration routes, underlying disease for which GCs were administered and, most importantly, study design (cross-sectional versus longitudinal). There is increasing evidence that early effects (days/weeks) may be opposite to late effects (months/years). It is agreed nowadays that in patients exposed to pharmacological doses of GCs increased bone resorption occurs early and is transient (1). Yet, few studies have addressed the changes of osteoclast function at the very beginning of treatment (20). Our previous and present findings, together with those of other studies, prompt the interest, even for strategies of prevention, for elucidating the subserving mechanisms.

Prior emphasis to explain these events had been placed on the effects of GCs on other hormonal axes and mineral metabolism, including PTH. However, the role of hyperparathyroidism (due to hypocalcaemic actions of GCs complemented by a direct action on parathyroid glands) has been recently questioned (29). We have found a decrease of PTH in the course
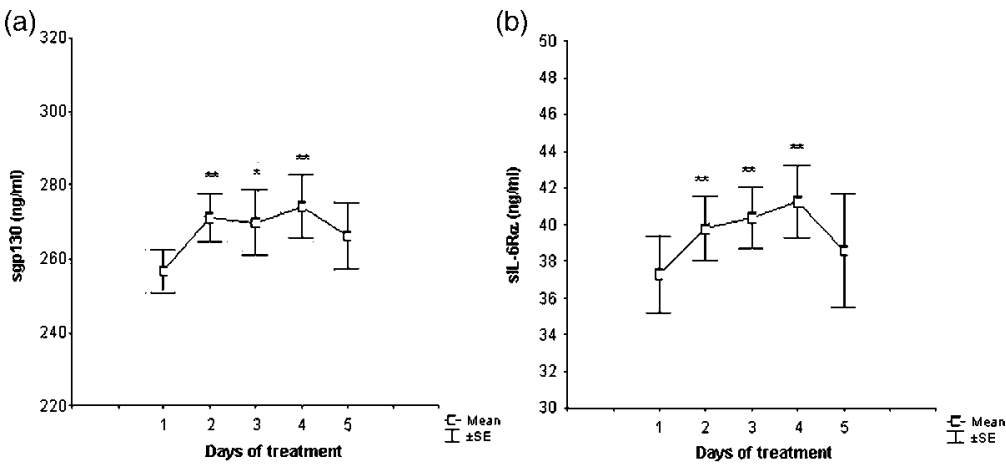

Figure 4 Effects of GC administration on serum sgp130 and SIL-6R $\alpha$ (absolute values). sgp130 (a) and sIL-6R $\alpha$ (b) were measured on morning fasting blood samples before (day 1) and each day during treatment (days 2-5). Data are expressed as mean \pm S.E.M. ${ }^{*} P<0.05$, ${ }^{\star \star} P<0.01$ by Wilcoxon matched pair test. 

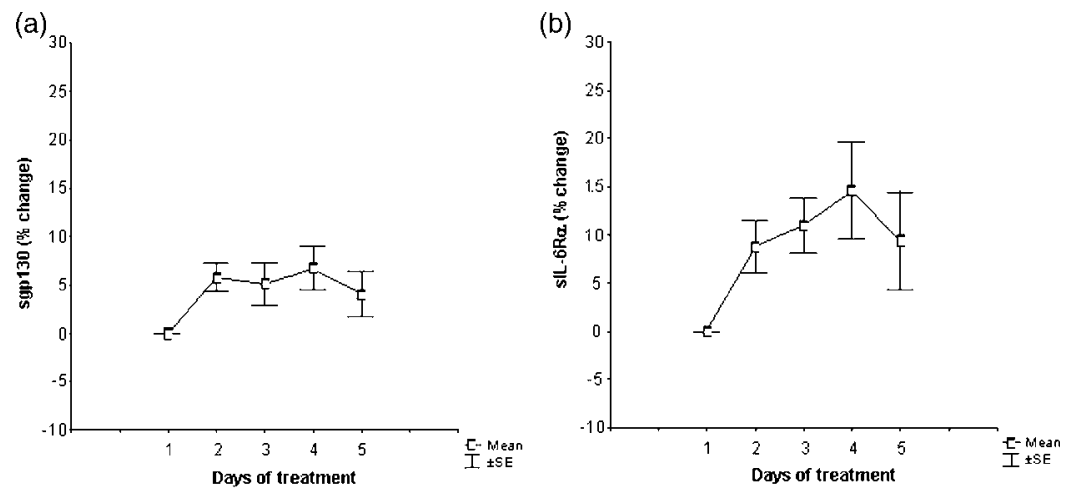

Figure 5 Effects of GC administration on serum sgp130 and sIL-6R $\alpha$ (percent values). sgp130 (a) and sIL-6R $\alpha$ (b) were measured on morning fasting blood samples before (day 1) and each day during treatment (days 2-5). Data are expressed as mean \pm S.E.M. of GC administration. Similarly, non-significant decrease of PTH in the course of GC therapy was reported by Pearce et al. (25). In fact, studies investigating serum PTH levels in GC-treated patients have yielded inconsistent results (29), possibly due to the fact that single random measurements do not reflect the overall pattern of PTH secretion. Bonadonna et al. have recently shown that GC treatment induces a redistribution of spontaneous PTH secretory dynamics by reducing the amount released in tonic fashion and increasing the amount released as pulses (30).

While the pathogenetic role of the classical systemic actions of GCs remains in the background, direct effects on bone cells have gained importance. IL- 6 is a wellrecognized osteoclastogenic cytokine. It promotes the differentiation of osteoclasts from progenitor cells and the action of mature osteoclasts (8). The cellular and molecular mechanisms of IL- 6 action on cells of the osteoclastic lineage are not fully understood. IL-6 could have direct effects, since available data support the presence of gp130 on osteoclast membrane, at least in some models (31). IL-6 also exerts indirect effects on osteoclastogenesis by altering the ratio of

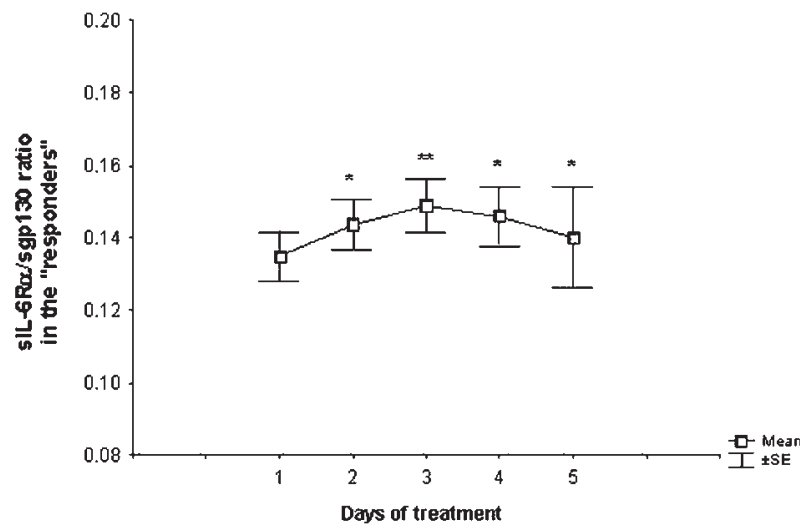

Figure 6 Effects of GC administration on serum sIL-6R $\alpha /$ sgp130 ratio in the responders $(n=19)$. sgp130 and sIL-6R $\alpha$ were measured on morning fasting blood samples before (day 1 ) and each day during treatment (days 2-5). Data are expressed as mean \pm S.E.M. ${ }^{*} P<0.05,{ }^{* *} P<0.01$ by Wilcoxon matched pair test.
RANKL/OPG produced by stromal and osteoblastic cells $(11-12)$. In different in vitro models adding IL-6 and sIL-6R $\alpha$ in the medium yielded an increased release of more RANKL than OPG (11). For osteoclastogenesis, an important role of sIL-6R $\alpha$ has been convincingly demonstrated in vitro $(10-11,17)$. To the best of our knowledge, the present report is the first that has addressed the changes of serum levels of sIL-6R $\alpha$ and sgp130 in patients given high-dose GCs. Our data clearly show that the vast majority of such patients (about 80\%) display increased sIL-6R $\alpha$ and sIL$6 \mathrm{R} \alpha / \mathrm{sgp} 130$ ratio in the first days of treatment. It is obvious that many sources may contribute to the increase of circulating sIL-6R $\alpha$. Numerous studies have documented that GCs are able to increase IL$6 \mathrm{R} \alpha$ expression in a variety of tissues (10, 32-33). With regard to the bone microenvironment, Vermes et al. have demonstrated that availability of the specific receptor subunit sIL-6R $\alpha$ is required for IL-6 signalling in human osteoblasts, the membrane form being inactive (34). Accordingly, it is logical to think that the proosteoclastogenic action of IL-6, at least in the part mediated by osteoblast activity, is a function of IL$6 /$ sIL-6R $\alpha$ complexes, that bind gp130 to activate specific intracellular pathways. Since the potentiating role of sIL- 6 R $\alpha$ for IL- 6 signalling is referred to as a general phenomenon, and GCs increase IL-6R $\alpha$ expression in many cells including osteoblasts, the early increase of osteoclast population and function in patients given GCs may find a further explanation in the increased availability of IL-6R $\alpha$. Interestingly enough, in patients with higher levels of sIL-6R $\alpha$ GCs administration yielded a decrease of sIL-6R $\alpha$ and sIL-6R $\alpha / \operatorname{sgp} 130$ ratio. We have no explanation for divergent patterns, since our responders and non-responders did not show differences in the history of disease, clinical presentation and response to treatment.

O'Brien et al. have recently emphasized the importance of the early phase of increased resorption, which is essential for the development of GC-induced bone loss in a murine model (35). Would such a key-role be confirmed in patients, sIL-6R $\alpha$ could represent a promising target for new anti-resorptive drugs. Interestingly enough, a humanized monoclonal antibody 
against the human IL-6R $\alpha$ (called myeloma receptor antibody, MRA, or tocilizumab) is currently under investigation in a number of diseases including adult rheumatoid arthritis, systemic juvenile idiopathic arthritis and multiple myeloma. MRA has been shown to compete for both the membrane-bound and the soluble forms of the human IL- $6 \mathrm{R} \alpha$, and to inhibit IL-6 function (36-37). To our knowledge, potential effects of MRA on GC-induced bone resorption has not yet been assessed.

Limitations of our study should be noted. First, we did not find any correlation between the increase of the bone resorption marker and the increase of serum sIL-6R $\alpha$ levels and sIL-6R $\alpha / \operatorname{sgp} 130$ ratio. The lack of correlation could be accounted for by the small sample size, the inter-individual variation and, most importantly, the multiplicity of mechanisms that mediate GC-induced bone resorption and early changes of relevant markers. In particular, direct actions of GCs on osteoclasts would be independent of any significant change in local and circulating concentrations of hormones, cytokines and their receptors. Second, serum IL-6 was always below or near the detection limit of our ELISA. We cannot exclude that a more sensitive assay could detect changes in the very low range of concentrations. Finally, serum levels of IL-6, sIL-6R $\alpha$ and sgp130 may not reflect their concentrations in the bone microenvironment. IL-6 is constitutively expressed by human osteoblasts in vitro, is measurable in bone marrow plasma and is detectable by immunohistochemistry in bone specimens (38). Since GCs admittedly exert opposite effects (i.e., inhibitory and stimulatory, respectively) on cellular expression of IL6 and sIL-6R $\alpha$, direct evidence of such effects in the bone microenvironment should be searched for.

In conclusion, we have reported for the first time that sIL-6R $\alpha$ and sIL-6R $\alpha /$ sgp130 ratio are precociously increased in the peripheral blood of the vast majority of patients given high-dose, intravenous GCs. The increase of systemically available sIL- $6 \mathrm{R} \alpha$ conceivably results in the enhancement of IL-6-dependent osteoclastogenesis. Consistently with previous in vitro studies, our data suggest a role for IL-6 signalling in the GC-induced increase of bone resorption. The role of such a mechanism in the bone loss observed in inflammatory and immune-mediated diseases (where abundancy of IL- 6 in the bone microenvironment is expected) requires further investigation.

\section{Acknowledgements}

We wish to thank patients and staff of CRESM for their co-operation in collecting data for this study. Dr A Dovio has been awarded one of the 2004 Prizes from the Società Italiana di Medicina Interna. This work was supported by grants from MIUR, Procter\&Gamble, Cassa di Risparmio di Saluzzo, Fondazione Ricerca
Biomedica and Fondazione Cavalieri Ottolenghi per le Neuroscienze.

\section{References}

1 Canalis E, Bilezikian JP, Angeli A \& Giustina A. Perspectives on glucocorticoid-induced osteoporosis. Bone 200434 593-598.

2 Van Staa TP, Leufkens HG, Abenhaim L, Zhang B \& Cooper C. Use of oral corticosteroids and risk of fractures. Journal of Bone and Mineral Research 200015 993-1000.

3 Weinstein RS, Chen JR, Powers CC, Stewart SA, Landes RD, Bellido T, Jilka RL, Parfitt AM \& Manolagas SC. Promotion of osteoclast survival and antagonism of bisphosphonate-induced osteoclast apoptosis by glucocorticoids. Journal of Clinical Investigation $20021091041-1048$.

4 Beavan S, Horner A, Bord S, Ireland D \& Compston J. Colocalization of glucocorticoid and mineralocorticoid receptors in human bone. Journal of Bone and Mineral Research 200116 1496-1504.

5 Bland R. Steroid hormone receptor expression and action in bone. Clinical Science $200098217-240$.

6 Patschan D, Loddenkemper K \& Buttgereit F. Molecular mechanisms of glucocorticoid-induced osteoporosis. Bone 200129 498-505.

7 Hofbauer LC, Kuhne CA \& Viereck V. The OPG/RANKL/RANK system in metabolic bone diseases. Journal of Musculoskeletal Neuronal Interactions $2004 \mathbf{4} 268-275$.

8 Wong PK, Campbell IK, Egan PJ, Ernst M \& Wicks IP. The role of the interleukin- 6 family of cytokines in inflammatory arthritis and bone turnover. Arthritis \& Rheumatism $2003 \mathbf{4 8}$ 1177-1189.

9 Heinrich PC, Behrmann I, Haan S, Hermanns HM, MullerNewen G \& Schaper F. Principles of interleukin (IL)-6-type cytokine signalling and its regulation. Biochemical Journal $2003 \mathbf{3 7 4}$ $1-20$.

10 Udagawa N, Takahashi N, Katagiri T, Tamura T, Wada S, Findlay DM, Martin TJ, Hirota H, Taga T, Kishimoto T \& Suda T. Interleukin (IL)-6 induction of osteoclast differentiation depends on IL-6 receptors expressed on osteoblastic cells but not on osteoclast progenitors. Journal of Experimental Medicine 1995182 $1461-1468$.

11 Palmqvist P, Persson E, Conaway HH \& Lerner UH. IL-6, leukemia inhibitory factor, and oncostatin $\mathrm{M}$ stimulate bone resorption and regulate the expression of receptor activator of NF-kappa B ligand, osteoprotegerin, and receptor activator of NF-kappa B in mouse calvariae. Journal of Immunology $20021693353-3362$.

12 O'Brien CA, Gubrij I, Lin SC, Saylors RL \& Manolagas SC. STAT3 activation in stromal/osteoblastic cells is required for induction of the receptor activator of NF-kappaB ligand and stimulation of osteoclastogenesis by gp130-utilizing cytokines or interleukin-1 but not 1,25-dihydroxyvitamin D3 or parathyroid hormone. Journal of Biological Chemistry $199927419301-19308$.

13 Hofbauer LC, Lacey DL, Dunstan CR, Spelsberg TC, Riggs BL \& Khosla S. Interleukin-1beta and tumor necrosis factor-alpha, but not interleukin-6, stimulate osteoprotegerin ligand gene expression in human osteoblastic cells. Bone 199925 255-259.

14 Castellino AM \& Chao MV. Trans-signaling by cytokine and growth factor receptors. Cytokine Growth Factor Reviews 19967 297-302.

15 Kamimura D, Ishihara K \& Hirano T. IL-6 signal transduction and its physiological roles: the signal orchestration model. Reviews of Physiology, Biochemistry and Pharmacology 2003149 1-38.

16 Lin SC, O'Brien CA \& Manolagas SC. Sex steroids decrease and glucocorticoids increase the levels of gp130 protein in bone marrow-derived stromal cells: correlation with altered IL-6 induced DNA-binding activity of Stat1 and Stat3 complexes. Journal of Bone and Mineral Research 199611 S161 (abstract).

17 Richards CD, Langdon C, Deschamps P, Pennica D \& Shaughnessy SG. Stimulation of osteoclast differentiation in vitro by mouse oncostatin M, leukaemia inhibitory factor, 
cardiotrophin-1 and interleukin 6: synergy with dexamethasone. Cytokine 200012 613-621.

18 Poser CM, Paty DW, Scheinberg L, McDonald WI, Davis FA, Ebers GC, Johnson KP, Sibley WA, Silberberg DH \& Tourtellotte WW. New diagnostic criteria for multiple sclerosis: guidelines for research protocols. Annals of Neurology 198313 $227-231$.

19 Ton FN, Gunawardene SC, Lee H \& Neer RM. Effects of low-dose prednisone on bone metabolism. Journal of Bone and Mineral Research 200520 464-470.

20 Dovio A, Perazzolo L, Osella G, Ventura M, Termine A, Milano E, Bertolotto A \& Angeli A. Immediate fall of bone formation and transient increase of bone resorption in the course of high-dose, short-term glucocorticoid therapy in young patients with multiple sclerosis. Journal of Clinical Endocrinology and Metabolism 200489 4923-4928.

21 Fujita T, Satomura A, Hidaka M, Ohsawa I, Endo M \& Ohi H. Acute alteration in bone mineral density and biochemical markers for bone metabolism in nephrotic patients receiving highdose glucocorticoid and one-cycle etidronate therapy. Calcified Tissue International 200066 195-199.

22 Godschalk MF \& Downs RW. Effect of short-term glucocorticoids on serum osteocalcin in healthy young men. Journal of Bone and Mineral Research 19883 113-115.

23 Nielsen HK, Charles P \& Mosekilde L. The effect of single oral doses of prednisone on the circadian rhythm of serum osteocalcin in normal subjects. Journal of Clinical Endocrinology and Metabolism 198867 1025-1030.

24 Prummel MF, Wiersinga WM, Lips P, Sanders GT \& Sauerwein HP. The course of biochemical parameters of bone turnover during treatment with corticosteroids. Journal of Clinical Endocrinology and Metabolism $1991 \mathbf{7 2} 382-386$.

25 Pearce G, Tabensky DA, Delmas PD, Baker HW \& Seeman E. Corticosteroid-induced bone loss in men. Journal of Clinical Endocrinology and Metabolism $1998 \mathbf{8 3} 801-806$.

26 Paglia F, Dionisi S, De Geronimo S, Rosso R, Romagnoli E, Raejntroph N, Ragno A, Celi M, Pepe J, D’Erasmo E \& Minisola S. Biomarkers of bone turnover after a short period of steroid therapy in elderly men. Clinical Chemistry $2001 \mathbf{4 7}$ 1314-1316.

27 Ardissone P, Rota E, Durelli L, Limone P \& Isaia GC. Effects of high doses of corticosteroids on bone metabolism. Journal of Endocrinological Investigation 200225 129-133.

28 Sasaki N, Kusano E, Ando Y, Nemoto J, limura O, Ito C, Takeda S, Yano K, Tsuda E \& Asano Y. Changes in osteoprotegerin and markers of bone metabolism during glucocorticoid treatment in patients with chronic glomerulonephritis. Bone $2002 \mathbf{3 0}$ $853-858$.

29 Rubin MR \& Bilezikian JP. Clinical review 151: The role of parathyroid hormone in the pathogenesis of glucocorticoid-induced osteoporosis: a re-examination of the evidence. Journal of Clinical Endocrinology and Metabolism 200287 4033-4041.

30 Bonadonna S, Burattin A, Nuzzo M, Bugari G, Rosei EA, Valle D, Iori N, Bilezikian JP, Veldhuis JD \& Giustina A. Chronic glucocorticoid treatment alters spontaneous pulsatile parathyroid hormone secretory dynamics in human subjects. European Journal of Endocrinology $2005152199-205$.

31 Gao Y, Morita I, Maruo N, Kubota T, Murota S \& Aso T. Expression of IL- 6 receptor and gp130 in mouse bone marrow cells during osteoclast differentiation. Bone 199822 487-493.

32 Polgar A, Brozik M, Toth S, Holub M \& Falus A. A synthetic corticosteroid, dexamethasone regulates generation of soluble form of interleukin- 6 receptor of human lymphocytes, in vitro. Acta Biologica Hungarica 200253 307-315.

33 Geisterfer M, Richards CD \& Gauldie J. Cytokines oncostatin M and interleukin 1 regulate the expression of the IL- 6 receptor (gp80, gp130). Cytokine 19957 503-509.

34 Vermes C, Jacobs JJ, Zhang J, Firneisz G, Roebuck KA \& Glant TT. Shedding of the interleukin-6 (IL-6) receptor (gp80) determines the ability of IL-6 to induce gp130 phosphorylation in human osteoblasts. Journal of Biological Chemistry $2002 \quad \mathbf{2 7 7}$ $16879-16887$.

35 O'Brien CA, Jia D, Plotkin LI, Bellido T, Powers CC, Stewart SA, Manolagas SC \& Weinstein RS. Glucocorticoids act directly on osteoblasts and osteocytes to induce their apoptosis and reduce bone formation and strength. Endocrinology $2004 \mathbf{1 4 5}$ 1835-1841.

36 Nishimoto N, Yoshizaki K, Miyasaka N, Yamamoto K, Kawai S, Takeuchi T, Hashimoto J \& Kishimoto T. Long-term safety and efficacy of anti-interleukin 6 receptor antibody (MRA) in patients with rheumatoid arthritis. Arthritis, Rheumatism 20039 (Suppl) S126 (abstract).

37 Yokota S, Miyamae T, Imagawa T, Iwata N, Katakura S, Mori M, Nishimoto N, Yoshizaki K, Woo P, Hirsch R \& Kishimoto T. Phase II trial of anti-IL-6 receptor antibody (MRA) for children with systemic-onset juvenile idipathic arthritis. Arthritis \& Rheumatism 20039 (Suppl) S429 (abstract).

38 Lisignoli G, Piacentini A, Toneguzzi S, Grassi F, Cocchini B, Ferruzzi A, Gualtieri G \& Facchini A. Osteoblasts and stromal cells isolated from femora in rheumatoid arthritis (RA) and osteoarthritis (OA) patients express IL-11, leukaemia inhibitory factor and oncostatin M. Clinical and Experimental Immunology 2000 $119346-353$.

Received 15 December 2005

Accepted 14 February 2006 